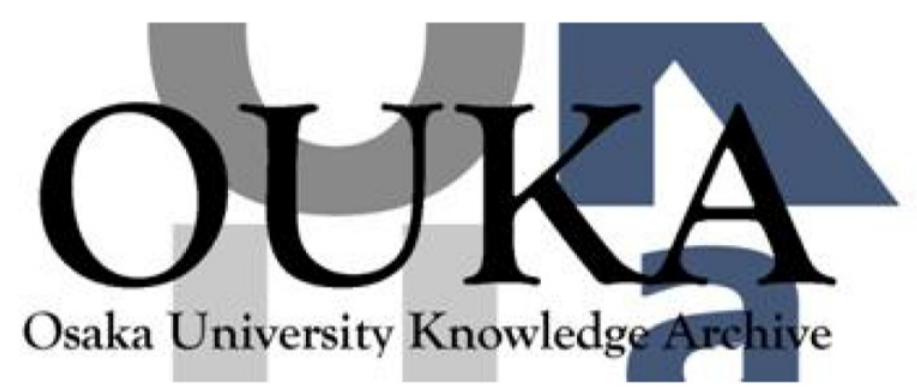

\begin{tabular}{|c|c|}
\hline Title & $\begin{array}{l}\text { Complex formation of collagen model peptides } \\
\text { with polyelectrolytes and stabilization of the } \\
\text { triple helical structure }\end{array}$ \\
\hline Author(s) & $\begin{array}{l}\text { Terao, Ken; Kanenaga, Ryoko; Sato, Takahiro et } \\
\text { al. }\end{array}$ \\
\hline Citation & Macromolecules. 45(1) p. 392-p. 400 \\
\hline Issue Date & $2011-12-07$ \\
\hline oaire:version & AM \\
\hline URL & https://hdl. handle. net/11094/81839 \\
\hline rights & $\begin{array}{l}\text { This document is the Accepted Manuscript } \\
\text { version of a Published Work that appeared in } \\
\text { final form in Macromolecules, } \odot \text { American } \\
\text { Chemical Society after peer review and } \\
\text { technical editing by the publisher. To access } \\
\text { the final edited and published work see } \\
\text { https://doi.org } / 10.1021 / \text { ma202176w. }\end{array}$ \\
\hline Note & \\
\hline
\end{tabular}

Osaka University Knowledge Archive : OUKA

https://ir. Library. osaka-u. ac. jp/

Osaka University 


\title{
Complex Formation of Collagen Model Peptides with Polyelectrolytes and Stabilization of the Triple Helical Structure
}

\author{
Ken Terao, ${ }^{\dagger}, \dot{t}, *$ Ryoko Kanenaga, ${ }^{\dagger}$ Takahiro Sato, ${ }^{\dagger}$ Kazunori Mizuno, ${ }^{\dagger}$ and Hans Peter Bächinger ${ }^{\dagger,},{ }^{*} *$
}

†Department of Macromolecular Science, Osaka University, 1-1, Machikaneyama-cho, Toyonaka, Osaka, 560-0043, Japan, *Research Department, Shriners Hospital for Children, Portland, Oregon 97239, and ${ }^{\S}$ Department of Biochemistry and Molecular Biology, Oregon Health \& Science University,

Portland, Oregon 97239

E-mail: kterao@chem.sci.osaka-u.ac.jp; hpb@shcc.org.

ABSTRACT: Small-angle X-ray scattering (SAXS) measurements were made for three collagen model peptides, H-(Gly-Pro-4-(R)-Hyp) ${ }_{9}-\mathrm{OH}, \mathrm{H}-(\text { Pro-4- }(R)-\mathrm{Hyp}-\mathrm{Gly})_{9}-\mathrm{OH}$, and H-(Gly-4-(R)-Hyp-4- $(R)-$ Hyp) ${ }_{9}-\mathrm{OH}$ with or without sodium polyacrylate (NaPAA) in $20 \mathrm{mM}$ and $100 \mathrm{mM}$ aqueous $\mathrm{NaCl}$ at $15^{\circ} \mathrm{C}$ and $75^{\circ} \mathrm{C}$. At $15^{\circ} \mathrm{C}$, almost all triple helical peptides form a complex with NaPAA when the molar ratio of acrylic acid unit to peptide molecules is larger than 10 whereas they are molecularly dispersed at $75{ }^{\circ} \mathrm{C}$. Furthermore, the attached triple helices appreciably extend the main chain of NaPAA, and the radius of gyration for the complex is at most twice larger than the single NaPAA chain. Circular dichroism measurements demonstrated that the complexation noticeably stabilizes the triple helical structure and the melting midpoint temperature $T_{\mathrm{m}}$ is $2-10^{\circ} \mathrm{C}$ higher than that for the solution without NaPAA. This stabilization was also observed for negatively charged sodium carboxymethylamylose and sodium hyaluronate as well as for positively charged poly(vinyl ammonium) chloride, but no appreciable stabilization of the triple helical structure by the polyelectrolytes was observed for an end-capped peptide Ac-(Gly-Pro-4-(R)-Hyp) ${ }_{9}-\mathrm{NH}_{2}$. These results indicate that the complex formation is due to the electrostatic attraction between polyelectrolytes and the opposite charges at the end of uncapped triple helical peptides.

\section{INTRODUCTION}

Some synthetic oligo-peptides having Gly-Xaa-Yaa triplet repeats, whose Xaa and Yaa are often composed of proline or 4- $(R)$-hydroxyproline, form a triple helix in solution at low temperature. Since this helical structure and sequences are similar to the triple helical part of natural collagen molecules, they are so-called collagen model (or mimic) peptides ${ }^{1}$ (CMP) or triple-helical peptides. ${ }^{2}$ This triple helical structure dissociates with raising temperature and the conformational change between triple helix and single-chain random coil is fully reversible, which is different from native collagen helices. Thus, these collagen model peptides have been well studied to determine the detailed conformation as well as to investigate the origin of thermal stability of the triple helices. $1,2,3,4,5,6$

The amine and carboxylic acid groups at the $\mathrm{N}$ - and $\mathrm{C}$-termini of the CMP are ionizable at acidic and basic $\mathrm{pH}$, so that the CMP triple helix and single-chain random coil are viewed as a tri-valent and monovalent cationic (anionic) species, respectively at acidic (basic) $\mathrm{pH}$. Furthermore, the ionization at the chain end destabilizes the triple helix. Therefore, the electrolytic character of the CMP provides interesting phenomena at interacting with polyelectrolytes. For example, since the attractive interaction between the polyelectrolyte and counter ions is definitively affectable by the ionic valence of the counter ions, polyelectrolytes should interact with triple helical CMPs much stronger than single chain CMPs. The complexation with triple-helical CMPs may change the conformation of the polyelectrolyte because the triple helices act as rigid graft chains of the polyelectrolyte main chain. On the other hand, the CMP triple helix may be stabilized by the neutralization of the end charges in the complex with the polyelectrolyte.

Recently, we found that the methanol solution of H-(Pro-Pro-Gly)5-OH (PPG5) became turbid by addition of polyacrylic acid (PAA), indicating the formation of poorly soluble complexes due to the 
attractive force between three N-termini and $\mathrm{COOH}$ groups of PAA. ${ }^{7}$ Furthermore, the addition of PAA into the methanol solution increased the thermal stability of the triple helix of this CMP as high as $30{ }^{\circ} \mathrm{C}$. Similar stabilization was also reported for trimerized CMPs by covalent bonds or interaction among non-collagenous domains. ${ }^{1,2,8,9,10,11}$ This is thus most likely due to the reduction of electrostatic repulsion force among the $N$-termini. However, this CMP-PAA complex was hardly dissolved in methanol; it was thus difficult to study this complex more extensively.

After some attempts, we found that thermal stability of triple helix for a more hydrophilic CMPs, that is, H-(Gly-Pro-4-(R)-Hyp) ${ }_{9}-\mathrm{OH}$ (GPO9) (1 in Chart 1), H-(Pro-4-(R)-Hyp-Gly) ${ }_{9}-\mathrm{OH}$ (POG9) (2), and H-(Gly-4- $(R)$-Hyp-4-(R)-Hyp) 9 -OH (GOO9) (3) in pure water significantly increases with the content of sodium polyacrylic acid (NaPAA) (5) and the mixtures were completely transparent at any composition of the two solutes, suggesting that the complexes have good solubility in water. We thus determined the molar mass and the dimensional properties of the complex consisting mainly of GPO9 and NaPAA by small-angle X-ray scattering (SAXS) at different temperatures. The thermal stability of the triple helices was also examined for these systems as well as those consisting of some other polyelectrolytes and low molecular-weight electrolytes shown in Chart 1 (6-10) to estimate the dominant effect of complex formation. As the reference, an end-capped peptide, acetyl-(Gly-Pro-4-(R)-Hyp) $6-\mathrm{NH}_{2}($ Ac$\left.(\mathrm{GPO})-\mathrm{NH}_{2}\right)(4)$, in which both end groups are not ionized in aqueous solution, was also studied to clarify the end effect.

Chart 1. Chemical structures of the investigated samples.<smiles>CC(C)NC(=O)N1CCC[C@H]1C(=O)N1C[C@@H](O)C[C@H]1C(=O)O</smiles>

GPO9

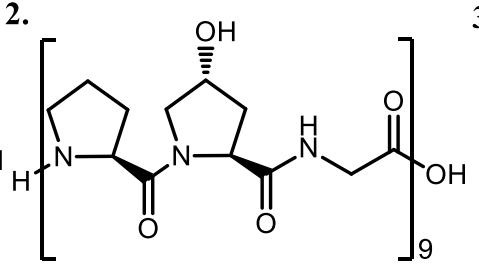

POG9

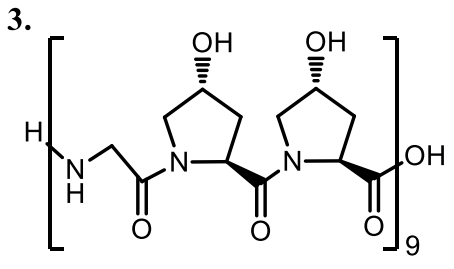

GOO9<smiles>CC(C)(C#N)NCC(=O)N1CCC[C@H]1C(=O)N1C[C@H](O)C[C@H]1C(N)=O</smiles>

5.<smiles>CC(C)(C)CC(C(=O)O[Na])C(C)(C)C</smiles>

NaPAA
8.<smiles>CC(C)(C)CC(N)C(C)(C)Cl</smiles>

9.

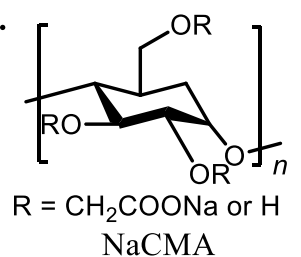

6.<smiles></smiles><smiles>O=CC1C[C@@H](C(=O)O[Na])C[C@H](C(=O)O[Na])C1</smiles>

cNaPAA3

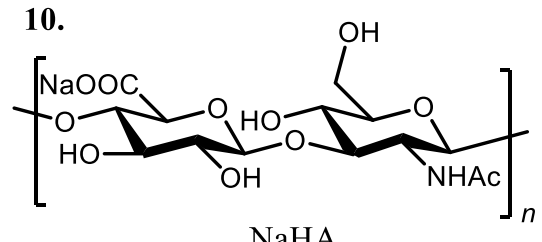

\section{EXPERIMENTAL SECTION}

Samples. Four peptide samples GPO9, POG9, GOO9, and Ac-(GPO6)- $\mathrm{NH}_{2}$ were synthesized with an ABI 433A synthesizer (Applied Biosynthesis, Foster, CA) using Fmoc amide acids and purified by solvent gradient HPLC; details including Mass spec characterization are described elsewhere. ${ }^{12}$ Molecular weights of the samples GPO9, POG9, GOO9, and Ac-(GPO6)- $\mathrm{NH}_{2}$ are 2423, 2423, 2567, and, 1663, respectively. Two NaPAA samples were prepared by neutralization of narrow dispersed PAA samples (Polymer Source) with aqueous sodium hydroxide. Their weight-average molecular weights $M_{\mathrm{w}}$ 's were estimated to be $3.04 \times 10^{4}$ and $2.51 \times 10^{4}$ for NaPAA323 and NaPAA267, respectively, from the sedimentation equilibrium data for the corresponding PAA samples. ${ }^{7,13}$ Their ratios of $z$-average molecular weight $M_{\mathrm{z}}$ to $M_{\mathrm{w}}$, a polydispersity index, were also estimated to be $c a$. 1.05 . Commercially available 1,3,5-pentanetricarboxylic acid and 1,3,5-cyclohexanetricarboxylic acid were neutralized by 
$\mathrm{NaOH}$ and used as oligo NaPAA. They are designated as NaPAA3 (6) and cNaPAA3 (7), respectively. A sodium carboxymethyl amylose sample NaCMA26K was prepared from enzymatically synthesized amylose ${ }^{14}$ by a known method, ${ }^{15}$ and the $M_{\mathrm{w}}$ and $M_{\mathrm{z}} / M_{\mathrm{w}}$ values were determined from the sedimentation equilibrium to be $2.57 \times 10^{4}$ and 1.04 , respectively. Molar fraction of carboxymethyl groups was estimated to be $0.40,0.03$, and 0.21 for $2-$, 3-, and 6-position, respectively, from a ${ }^{1} \mathrm{H}$ NMR measurement for fully hydrolyzed sample in deuterated sulfuric acid $(5 \mathrm{M}),{ }^{16}$ and hence, the degree of substitution is 0.64. A polyvinyl amine hydrochloric acid sample PVAm310K was synthesized by free radical polymerization and purified by fractional precipitation. The $M_{\mathrm{w}}$ and the ratio of $M_{\mathrm{w}}$ to the number-average molecular weight of the sample was determined to be $3.1 \times 10^{4}$ and 1.18 from multiangle laser light scattering equipped with size exclusion chromatography. ${ }^{17}$ A native sodium hyaluronic acid (NaHA) sample from rooster comb purchased from Wako was also used in this study.

Small-angle X-ray scattering (SAXS). SAXS measurements were made for GPO9, NaPAA (NaPAA323 or NaPAA267), and their mixtures, dissolved in $20 \mathrm{mM}$ or $100 \mathrm{mM}$ aqueous sodium chloride all at $15^{\circ} \mathrm{C}$ and $75^{\circ} \mathrm{C}$. The composition of each solution is specified in terms of the total solute mass concentration $c$ and the molar ratio $\alpha$ of the NaPAA monomer unit to the collagen model peptide in what follows. The latter was chosen to be 3, 10, and 30, in the SAXS measurements. Scattering intensities $I(q)$ at the absolute value $q$ of the scattering vector were measured on Rigaku R-AXIS VII imaging plates at the BL40B2 beamline in SPring-8 (Hyogo, Japan) or the BL-10C beamline in KEKPF (Ibaraki, Japan). Intensity of the direct beam was measured by using ionic chambers at the upper and lower ends of the capillary to correct the $I(q)$ data. The wavelength, the camera length, and the accumulation time were chosen to be $0.10-0.15 \mathrm{~nm}, 1500-2000 \mathrm{~cm}$, and $300 \mathrm{sec}$, respectively. The actual camera length and the center of the beam on the Imaging plates were determined by powder diffraction of the silver behenate. Solvent and four solutions with different $c$ were filled in a $1.5 \mathrm{~mm}$ quartz capillary and measured to determine the excess scattering intensity $\Delta I(q)$ as the difference in $I(q)$ between the solution and solvent. The SAXS measurements were also made for POG9, GOO9, and their mixtures with NaPAA267 at the ratio $\alpha$ of 30 in $20 \mathrm{mM}$ aqueous $\mathrm{NaCl}$ at $15{ }^{\circ} \mathrm{C}$ and $75{ }^{\circ} \mathrm{C}$.

In the aqueous solution, NaPAA and CMP may form complexes with different aggregation numbers, but here the complexes are regarded as a single scattering component for simplicity. Then, the solution of the mixture of NaPAA and CMP contains three scattering components, CMP (the component 1), NaPAA (the component 2), and their complex (the component 3) in general. The component 1 is the triple helix or single-chain random coil of CMP, and the coexistence of the two species are not considered in what follows. According to the SAXS theory, ${ }^{18} \Delta I(q) / c$ for a solution containing three scattering components at infinite dilution is written as

$$
\left[\frac{\Delta I(q)}{K c}\right]_{c=0}=w_{1} \Delta z_{1}^{2} M_{1} P_{1}(q)+w_{2} \Delta z_{2}^{2} M_{2} P_{2}(q)+w_{3} \Delta z_{3}^{2} M_{3} P_{3}(q)
$$

where $w_{i}, \Delta z_{i}, M_{i}$, and $P_{i}(q)$ are the weight fraction in the total solute, excess electron density, molar mass, and particle scattering function of the component $i$, respectively, and $K$ is the optical constant which is independent of the solute. The excess electron density $\Delta z_{i}$ is given by

$$
\Delta z_{i}=z_{i}-v_{i} \rho_{\mathrm{e}, \mathrm{s}}
$$

Here, $z_{i}$ is the number of moles of electrons per unit mass of the component $i, \rho_{\mathrm{e}, \mathrm{s}}$ the electron density of the solvent, and $v_{i}$ the partial specific volume of the component $i$. The value of $v_{2}$ was determined from the specific density increment $\left(\partial \rho / \partial c_{i}\right)_{\mu}$ at fixed chemical potential of diffusible components for NaPAA in $20 \mathrm{mM}$ and $100 \mathrm{mM}$ aqueous $\mathrm{NaCl}$ at $15^{\circ} \mathrm{C}$ and $75^{\circ} \mathrm{C}$. On the other hand, $v_{1}$ for the peptide samples were used for the previously obtained values ${ }^{19}$ in pure water because it is infeasible to determine $v_{1}$ for dialyzed small peptide solutions; this may not cause a significant error because of the low saline concentrations $(20 \mathrm{mM}$ and $100 \mathrm{mM})$ in the present study. The value of $v_{3}$ was calculated from $v_{1}$ and 
$v_{2}$ (see below). The optical constant $K$ was determined by using the scattering data for aqueous solutions of NaPAA323, NaPAA267, GOO9, or GPO9.

Circular Dichroism (CD). Circular dichroism measurements were made for GPO9, Ac-(GPO9)- $\mathrm{NH}_{2}$, POG9, GOO9 with or without NaPAA323, NaPAA267, NaPAA3, cNaPAA3, NaCMA26K, PVAm310K, or NaHA, in 0, 20, or $100 \mathrm{mM}$ aqueous $\mathrm{NaCl}$ using a JASCO J720WO or AVIV 202 spectropolarimeter both equipped with a Peltier thermostated cell holder and a $1 \mathrm{~mm}$ path length rectangular quartz cell. Temperature scans were recorded at fixed wavelength and at $6{ }^{\circ} \mathrm{C} \mathrm{h}^{-1}$ or $10^{\circ} \mathrm{C}$ $\mathrm{h}^{-1}$ to determine the molar ellipticity $[\theta]$ to estimate the melting midpoint temperature $T_{\mathrm{m}}$ of the triple helices; wavelength scans were evaluated in the range of wavelength between 210 and $260 \mathrm{~nm}$ at fixed temperatures.

\section{RESULTS AND DISCUSSION}

Complex Formation of NaPAA and GPO9. As indicated by eq $1, K c / \Delta I(q)$ at $c=0$ and $q=0$ is directly related with the complex formation. To obtain the limiting scattering function, we analyzed the scattering data using the Berry square root plot. Figure 1 is an example of $[K c / \Delta I(q)]^{1 / 2}$ vs $q^{2}$ plots $^{20}$ for the mixture of GPO9 and NaPAA267 $(\alpha=10)$ in $100 \mathrm{mM}$ aqueous $\mathrm{NaCl}$ at $75{ }^{\circ} \mathrm{C}$ and $15^{\circ} \mathrm{C}$. Filled circles indicate $[K c / \Delta I(q)]^{1 / 2}$ at infinite dilution, $[K c / \Delta I(q)]_{c=0}^{1 / 2}$, determined using plots of $[K c / \Delta I(q)]^{1 / 2}$ vs $c$. The obtained data points were extrapolated to $q^{2}=0$ by a straight line to determine $[K c / \Delta I(0)]_{c=0}{ }^{1 / 2}, P(q)$, and the $z$-average radius of gyration $\left\langle S^{2}>_{\mathrm{z}}\right.$. We note that the data for pure $\mathrm{NaPAA}$ in $20 \mathrm{mM} \mathrm{NaCl}$ were not analyzed because the extrapolation of the scattering intensity to zero angle was infeasible probably due to the significant intramolecular electrostatic interactions.
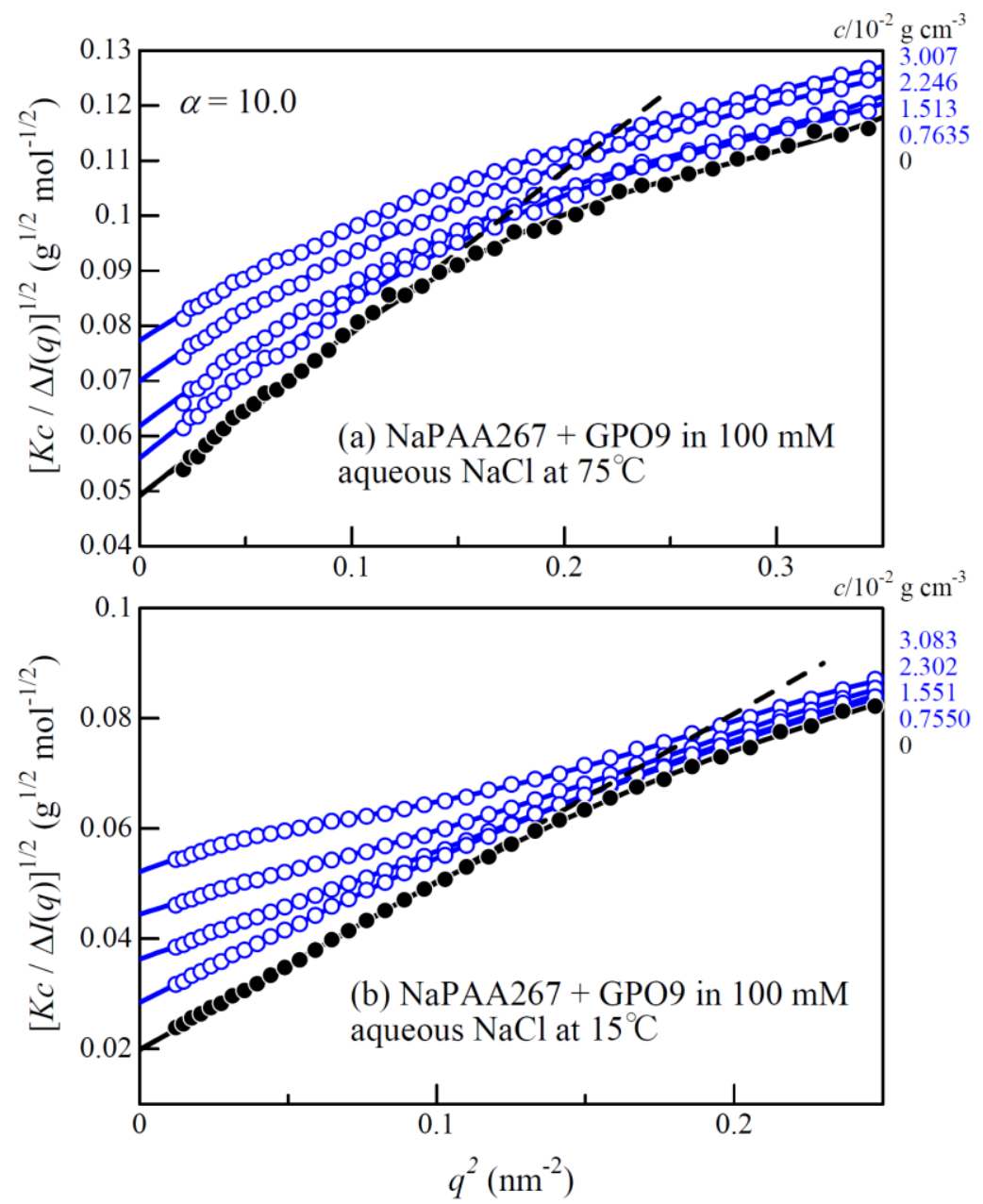

Figure 1. Plots of $[K c / \Delta I(q)]^{1 / 2}$ vs $q^{2}$ for NaPAA267 + GPO9 $(\alpha=10.0)$ in $100 \mathrm{mM}$ aqueous $\mathrm{NaCl}$ at $75^{\circ} \mathrm{C}(\mathrm{a})$ and $15^{\circ} \mathrm{C}(\mathrm{b})$. Filled symbols indicate the data extrapolated to $c=0$. 
The obtained $[K c / \Delta I(0)]_{c=0}{ }^{1 / 2}$ at $15{ }^{\circ} \mathrm{C}$ are 0.404 times smaller than that at $75{ }^{\circ} \mathrm{C}$, corresponding to 6.1 times larger scattering intensity at $15^{\circ} \mathrm{C}$, indicating complex formation between NaPAA and GPO9.

If the CMP and NaPAA exist in the mixture solution independently without complexation, eq 1 reduces in the limit of $q=0$ to

$$
\left(\frac{M_{\mathrm{c}}}{\alpha}+\frac{M_{2}}{n}\right)\left[\frac{\Delta I(0)}{K c}\right]_{c=0}=\frac{\Delta z_{1}^{2} M_{\mathrm{c}} M_{1}}{\alpha}+\frac{\Delta z_{2}^{2} M_{2}^{2}}{n} \quad \text { (no complexation) }
$$

where $n$ is the degree of polymerization of NaPAA, $M_{\mathrm{c}}$ the molar mass of GPO9, and $M_{1}$ is equal to $M_{\mathrm{c}}$ and $3 M_{\mathrm{c}}$ when the component 1 is the single-chain and triple helix, respectively. Figure 2 thus illustrates the experimental $\left\{\left[\left(M_{\mathrm{c}} / \alpha\right)+\left(M_{2} / n\right)\right][\Delta I(0) / K c]_{c=0}\right\}^{1 / 2}$ plotted against $\alpha^{-1}$ and that at $75^{\circ} \mathrm{C}$ (red symbols) are close to the red solid lines indicating values calculated by eq 3 with $M_{1}=M_{\mathrm{c}}$, demonstrating the all components are molecularly dispersed at the temperature. This is reasonable because CD spectra for GPO9 with and without NaPAA showed that all GPO9 chains take the random coil conformation at $75^{\circ} \mathrm{C}$ (see Supporting Information).

On the other hand, the experimental data at $15{ }^{\circ} \mathrm{C}$ (blue symbols) are significantly larger than the calculated values from eq 3 with $M_{1}=M_{\mathrm{c}}$ and $3 M_{\mathrm{c}}$ (the red solid and dashed lines), definitely indicating the complex formation between NaPAA and GPO9, although the CD spectra at $15{ }^{\circ} \mathrm{C}$ shown in Supporting Information does not change by addition of NaPAA. The CD spectra rather indicate that the triple helix of GPO9 is stable even in the complex with NaPAA at $15{ }^{\circ} \mathrm{C}$.

If all CMP triple helices form complexes with NaPAA chains in the solution at $15{ }^{\circ} \mathrm{C}$, the degree of complexation of each NaPAA chain becomes $\alpha^{-1}(\alpha \geq 1)$, and eq 1 is simplified as

$$
\left(\frac{M_{\mathrm{c}}}{\alpha}+\frac{M_{2}}{n}\right)\left[\frac{\Delta I(0)}{K c}\right]_{c=0}=n\left(\Delta z_{1} \frac{M_{\mathrm{c}}}{\alpha}+\Delta z_{2} \frac{M_{2}}{n}\right)^{2} \quad \text { (full complexation) }
$$

This equation shows that $\left\{\left[\left(M_{\mathrm{d}} / \alpha\right)+\left(M_{2} / n\right)\right][\Delta I(0) / K c]_{c=0}\right\}^{1 / 2}$ increases as a linear function of $\alpha^{-1}$. The solid blue lines in Figure 2 indicate theoretical values in the case of the full complexation, calculated from eq 4, which excellently fit the experimental data at $\alpha=30$ and 10 . This demonstrates that almost all GPO9 chains form complexes with both NaPAA of different molecular weights. Similar results were obtained for POG9 and GOO9 with NaPAA at $\alpha=30$. 


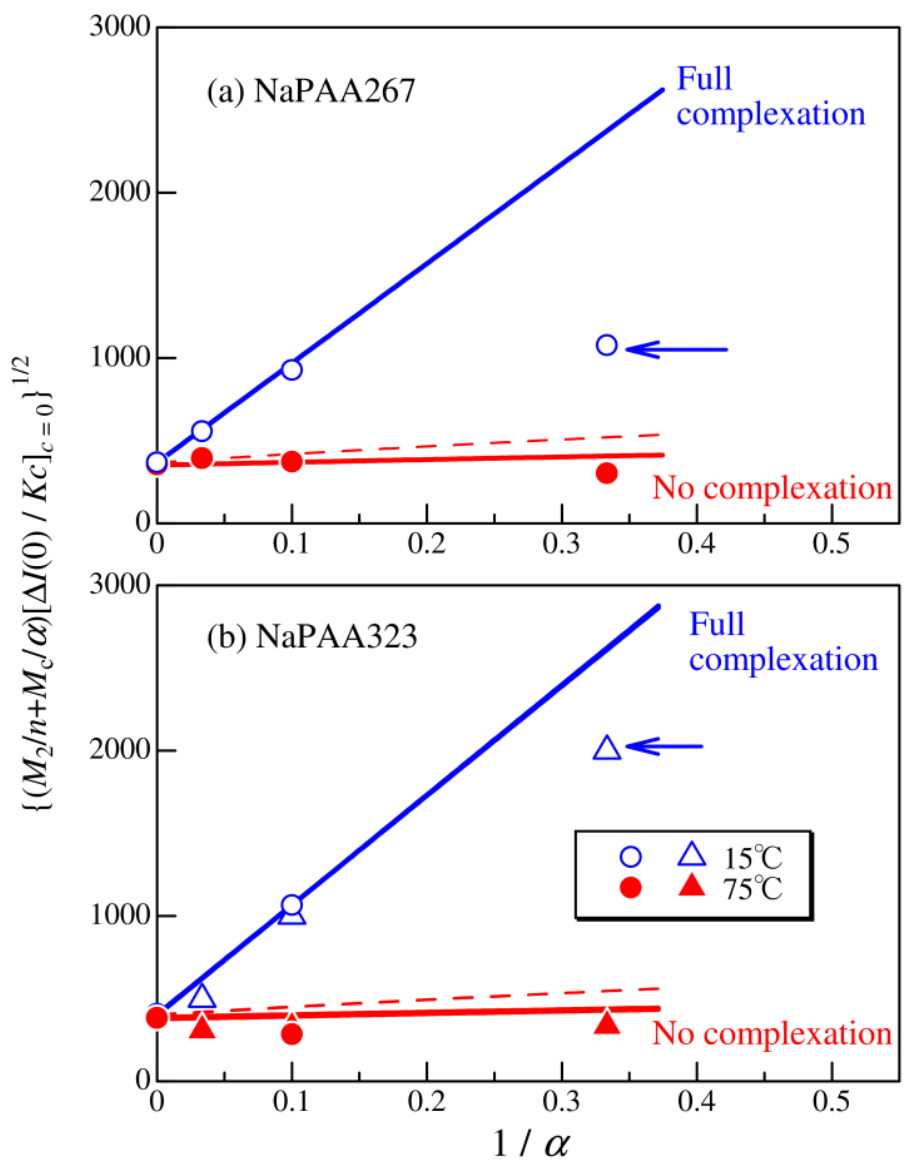

Figure 2. Plots of $\left\{\left[\left(M_{\mathrm{c}} / \alpha\right)+\left(M_{2} / n\right)\right][\Delta I(0) / K c]_{c=0}\right\}^{1 / 2}$ vs $1 / \alpha$ for NaPAA267 (a) and NaPAA323 (b) in $100 \mathrm{mM}$ (circles) and $20 \mathrm{mM}$ (triangles) aqueous $\mathrm{NaCl}$ at $75{ }^{\circ} \mathrm{C}$ (red filled symbols) and $15^{\circ} \mathrm{C}$ (blue open symbols). Solid blue lines, dashed red lines, and solid red lines indicate the calculated values by using eq 4 (all peptide form a complex with NaPAA), eq 3 with $M_{1}=3 M_{c}$ (triple helix $+\mathrm{NaPAA}$ ), and eq 3 with $M_{1}=M_{\mathrm{c}}$ (molecularly dispersed), respectively.

On the contrary, solutions including larger amounts of GPO9 compared to NaPAA, that is, $\alpha=3$, have intermediate scattering intensity between those calculated from eqs 3 and 4 . This indicates that not all GPO9 molecules form a complex with NaPAA, though the number of negative charges of NaPAA in solution is three times larger than that of GPO9 molecules. If the degree of complexation of each NaPAA chain is $f\left(\leq \alpha^{-1}\right)$, eq 1 can be rewritten as

$$
\left(\frac{M_{\mathrm{c}}}{\alpha}+\frac{M_{2}}{n}\right)\left[\frac{\Delta I(0)}{K c}\right]_{c=0}=n\left(\Delta z_{1} M_{\mathrm{c}} f+\Delta z_{2} \frac{M_{2}}{n}\right)^{2}+3 \Delta z_{1}^{2} M_{\mathrm{c}}^{2}\left(\frac{1}{\alpha}-f\right)
$$

since all GPO9 molecules take triple helices at $15{ }^{\circ} \mathrm{C}$. When the experimental results at $\alpha=3$ are substituted into the left-hand side of eq 5, the $f$ values were estimated to be 0.12 in $100 \mathrm{mM}$ aqueous $\mathrm{NaCl}$ and 0.24 in $20 \mathrm{mM}$, which correspond to that $36 \%$ and $72 \%$ of the GPO9 triple helix form complexes with $\mathrm{NaPAA}$ in 100 and $20 \mathrm{mM}$ aqueous $\mathrm{NaCl}$, respectively: The degree of complexation (or the binding constant) is higher in lower ionic strength. This complex formation is therefore most likely due to the electrostatic attraction between $\mathrm{COO}^{-}$groups of NaPAA and three $\mathrm{N}$ termini of GPO9 triple helices. It seems that the triple helical GPO9's attach rather regularly along the NaPAA chain because of the electrostatic repulsion and steric hindrance between neighboring GPO9 triple helices (cf. Figure $3)$. 


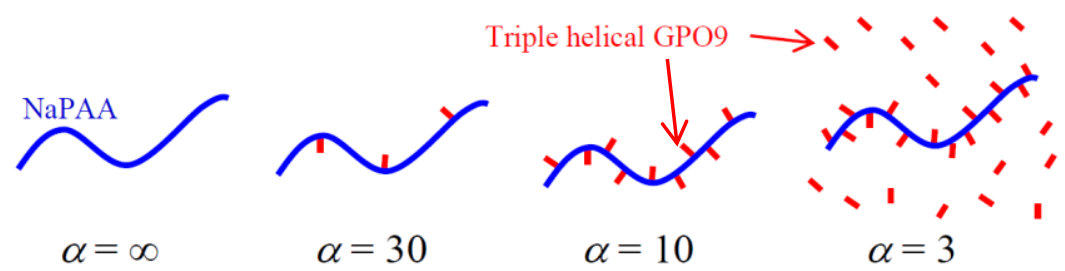

Figure 3. Schematic representation of complex formation for investigated $\alpha$ at $15{ }^{\circ} \mathrm{C}$.

Strictly speaking, $f$ depends on $c$, if the solution is in the association-dissociation equilibrium. Although the SAXS data were extrapolated to the zero $c, f$ obtained above are probably the values in the vicinity of $5 \times 10^{-3} \mathrm{~g} \mathrm{~cm}^{-3}$, that is the lowest $c$ where the SAXS measurements were made.

Global Conformation of the Complex. The shape of the complex in Figure 3 looks like comb polymers. Since the main chain of regular comblike polymers can be extended in a good solvent ${ }^{21}$ and even in theta solvents ${ }^{22}$ compared with the corresponding linear polymer without the side chains, NaPAA main chains of the current complex would have larger dimensions than the free NaPAA chains.

Here, we only consider the conformation of the complex at the full complexation at $\alpha=10$ and 30 at $15^{\circ} \mathrm{C}$. In this case, eq 1 is reduced to

$$
\begin{aligned}
{\left[\frac{\Delta I(q)}{K c}\right]_{c=0} } & =\frac{n\left[\Delta z_{1}\left(M_{\mathrm{c}} / \alpha\right)+\Delta z_{2}\left(M_{2} / n\right)\right]^{2}}{\left(M_{\mathrm{c}} / \alpha\right)+\left(M_{2} / n\right)} P_{3}(q) \\
& =\frac{n\left[\Delta z_{1}\left(M_{\mathrm{c}} / \alpha\right)+\Delta z_{2}\left(M_{2} / n\right)\right]^{2}}{\left(M_{\mathrm{c}} / \alpha\right)+\left(M_{2} / n\right)}\left(1-\frac{1}{3}\left\langle S^{2}\right\rangle_{z, 3} q^{2}+\cdots\right)
\end{aligned}
$$

and we can obtain the radius of gyration $\left\langle S^{2}\right\rangle_{z, 3}{ }^{1 / 2}$ of the complex from the angular dependence of $[\Delta I(q) / K c]_{c=0}$.

As shown in Table 1, the radii of gyration $\left\langle S^{2}\right\rangle_{\mathrm{z}, 3}{ }^{1 / 2}$ for $\alpha=10$ and 30 at $15^{\circ} \mathrm{C}$ are appreciably larger than that $\left\langle S^{2}\right\rangle_{\mathrm{z}, 2} 1^{1 / 2}$ for corresponding NaPAA without complexation $($ at $\alpha=\infty$ ). Considering the contour length of NaPAA is 8 to 10 times longer than the triple helical GPO9, this high $\left\langle S^{2}\right\rangle_{\mathrm{z}, 3}{ }^{1 / 2}$ is most likely due to the extension of the main chain. Furthermore, Kratky plots $\left[q^{2} P_{2}(q)\right.$ or $q^{2} P_{3}(q)$ vs $\left.q\right]$ for pure NaPAA, $\alpha=10$, and $\alpha=30$ illustrated in Figure 4 indicates the $q^{2} P_{2}(q)$ or $q^{2} P_{3}(q)$ value in finite $q$ range remarkably decreases with decreasing $\alpha$. It should be noted that the $P_{3}(q)$ and then $\left\langle S^{2}\right\rangle_{\mathrm{z}, 3}{ }^{1 / 2}$ for $\alpha=30$ mixtures of GOO9 and POG9 are essentially the same as those for GPO9 and hence omit them in the following analysis.

\begin{tabular}{|c|c|c|c|}
\hline \multirow[b]{2}{*}{$\alpha$} & \multicolumn{3}{|c|}{$\begin{array}{c}<S^{2}>_{\mathrm{z}, 2}{ }^{1 / 2},<S^{2}>_{\mathrm{z}, 3}{ }^{1 / 2} \\
(\mathrm{~nm})\end{array}$} \\
\hline & $\begin{array}{l}\text { NaPAA267 in } 100 \mathrm{mM} \\
\mathrm{NaCl}\end{array}$ & $\begin{array}{c}\text { NaPAA323 in } 100 \mathrm{mM} \\
\mathrm{NaCl}\end{array}$ & $\begin{array}{c}\text { NaPAA323 in } 20 \mathrm{mM} \\
\mathrm{NaCl}\end{array}$ \\
\hline $\begin{array}{l}\infty \text { (pure } \\
\text { NaPAA) }\end{array}$ & 5.7 & 6.7 & \\
\hline 30 & 7.3 & & 6.4 \\
\hline 10 & 9.6 & 10.9 & 10.3 \\
\hline
\end{tabular}

Table 1. Radii of Gyration for NaPAA and NaPAA-GPO9 complex in $100 \mathrm{mM}$ and $20 \mathrm{mM}$ aqueous $\mathrm{NaCl}$ at $15^{\circ} \mathrm{C}$.

First, we analyzed $P_{2}(q)$ for pure NaPAA267 and NaPAA323 in $100 \mathrm{mM}$ aqueous $\mathrm{NaCl}$ (shown by red circles in panels (a) and (b) in Figure 4) by the wormlike cylinder model, characterized by the contour length $L_{\mathrm{m}}$, the Kuhn segment length $\lambda_{\mathrm{m}}{ }^{-1}$ (stiffness parameter), and the cylinder diameter $d^{23}$ 
The fitting results are indicated by red solid curves in the panels, and the three parameters, $h_{\mathrm{m}}\left(\equiv L_{\mathrm{m}} / n\right)$, $\lambda_{\mathrm{m}}{ }^{-1}$, and $d$ obtained by the fitting were $0.26 \pm 0.01 \mathrm{~nm}, 3.3 \pm 0.3 \mathrm{~nm}$, and $1.5 \pm 0.1 \mathrm{~nm}$, respectively; the chain stiffness is fairly comparable with the previously estimated values. ${ }^{24}$

Assuming that the GPO9 attaches at regular intervals, the NaPAA-GPO9 complex may be modeled by the wormlike comb model (see Appendix). When the contour length $L_{\mathrm{s}}$ and the Kuhn segmtent length $\lambda_{\mathrm{s}}{ }^{-1}$ for the side groups are reasonably assumed to be $8.2 \mathrm{~nm}$ and $\infty$ from our recent SAXS data for GPO9, ${ }^{19} P_{3}(q)$ may be calculated with the remaining parameters $L_{\mathrm{m}}, \lambda_{\mathrm{m}}{ }^{-1}$, and the chain thickness parameter $d_{\mathrm{B}}$. A curve fitting procedure was employed to determine those parameters. Theoretical curves thus obtained (black and blue solid curves in panels (a)-(c) in Figure 4) fit the experimental data well, indicating that the regularly-branched wormlike comb model is suitable to describe the shape of the complex in solution. The obtained parameters also explain the experimental $\left\langle S^{2}\right\rangle_{z, 3}$ data since they are fitted by the theoretical radius of gyration $\left\langle S^{2}\right\rangle_{\text {calc }}$ calculated by eq 10 with the parameters obtained from $P_{3}(q)$ as shown in panel (d) in Figure 4. Whereas almost the same $h_{\mathrm{m}}(=0.26 \pm 0.01 \mathrm{~nm})$ and $d_{\mathrm{B}}$ $(=0.15 \pm 0.01 \mathrm{~nm})$ as those for pure NaPAA were obtained for all systems shown in Figure $4, \lambda_{\mathrm{m}}{ }^{-1}$ 's at $\alpha=10$ and 30 are appreciably larger than that for NaPAA. Figure 5 displays the plot of $\lambda_{\mathrm{m}}{ }^{-1}$ against $1 / \alpha$ for the complexes in 100 and $20 \mathrm{mM} \mathrm{NaCl}$ at $15^{\circ} \mathrm{C}$. The stiffness of the main chain increases linearly with $1 / \alpha$ and reaches twice the value than that for NaPAA. This is most likely due to the interaction between the side GPO9 chains and the main NaPAA chain. On the one hand, $\lambda_{\mathrm{m}}{ }^{-1}$ does not appreciably depend on the ionic strength whereas the intrinsic viscosities for NaPAA increase significantly with decreases the ionic strength. ${ }^{25}$ This seems to be rather unusual but possibly because the interaction between triple helical GPO9 and NaPAA becomes more attractive with decreasing $\mathrm{NaCl}$ concentration and compensates the increase of the electrostatic excluded-volume effects.
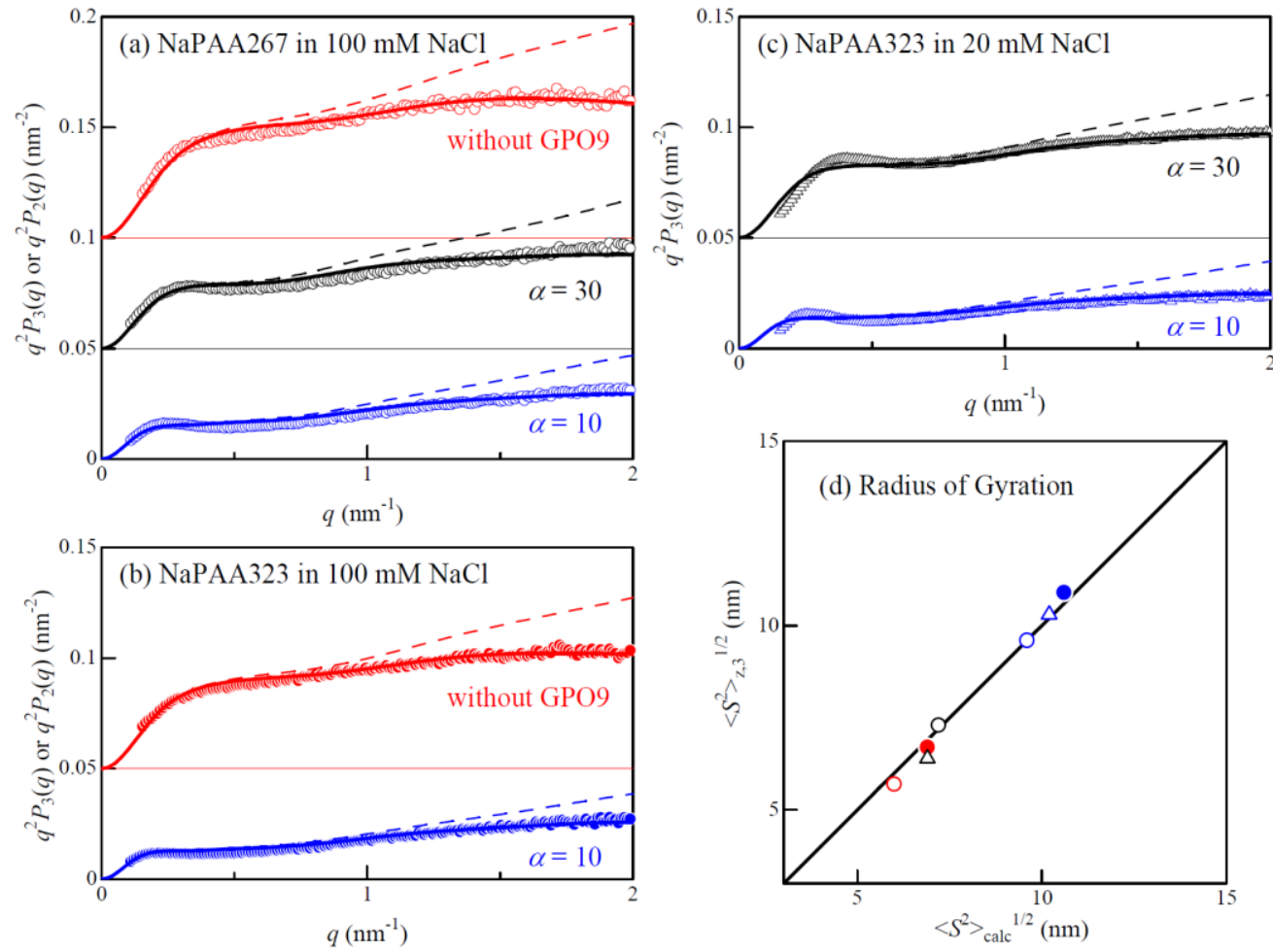

Figure 4. Kratky plots for (a) NaPAA267 and (b) NaPAA323 both in $100 \mathrm{mM}$ aqueous $\mathrm{NaCl}$, and (c) $\mathrm{NaPAA} 323$ in $20 \mathrm{mM}$ aqueous $\mathrm{NaCl}$ with or without indicated GPO9 all at $15{ }^{\circ} \mathrm{C}$. Solid curves are the theoretical values calculated for the wormlike combs with the parameters listed in the text. Dashed curve is those for infinite thin chains $\left(d_{\mathrm{B}}=0\right)$. (d) Comparison between the experimental radius of gyration $\left\langle S^{2}>_{z, 3}{ }^{1 / 2}\right.$ and calculated one $\left\langle S^{2}>_{\text {calc }}{ }^{1 / 2}\right.$ from the wormlike chain parameters estimated from the scattering functions. Symbols are the same as those in panels (a) - (c). 


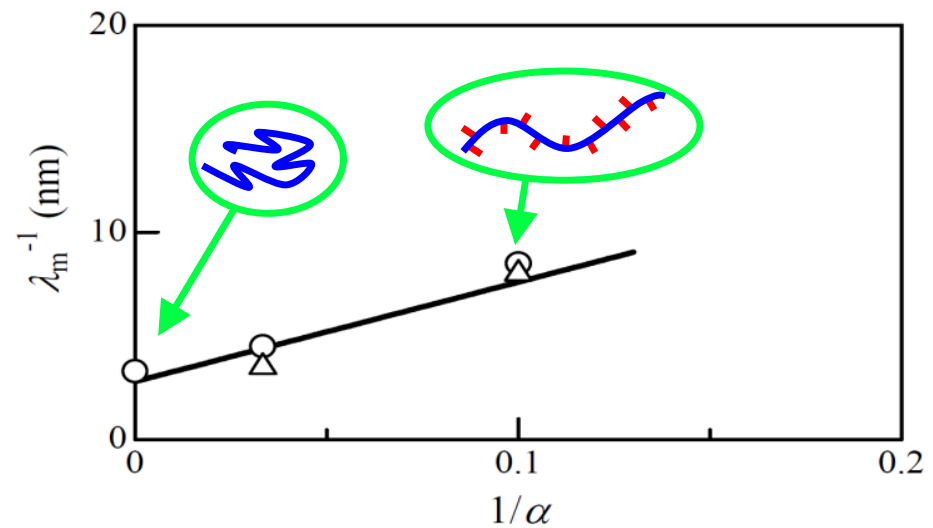

Figure 5. Composition $(1 / \alpha)$ dependence of the main chain stiffness $\lambda_{\mathrm{m}}{ }^{-1}$ for NaPAA and GPO9 complexes in $100 \mathrm{mM}$ (open circles) and $20 \mathrm{mM}$ (triangles) at $15^{\circ} \mathrm{C}$.

Stabilization of Triple Helical Structure of GPO9 in the Presence of NaPAA. The molar ellipticity $[\theta]_{225}$ at $\lambda_{0}=225 \mathrm{~nm}$ remarkably reflects the conformation of peptide chain. Figure 6 thus displays those for GPO9 triple helices in the presence of various amounts of NaPAA in pure water at $225 \mathrm{~nm}$ wavelength plotted against temperature. Except for the conformational transition region $\left(35^{\circ} \mathrm{C}\right.$ $\left.-55^{\circ} \mathrm{C}\right),[\theta]_{225}$ obey straight lines. Thus those for triple helices $\left([\theta]_{\text {helix }}\right)$ and single coil $\left([\theta]_{\text {coil }}\right)$ can be estimated as shown in the figure and therefore the helix content $F$ defined by

$$
[\theta(T)]=F(T)[\theta(T)]_{\text {helix }}+[1-F(T)][\theta(T)]_{\text {coil }}
$$

are plotted against temperature in the panel (b) of the figure. The melting midpoint temperatures $T_{\mathrm{m}}$ 's are determined as the temperature at $F=0.5$. Although the $T_{\mathrm{m}}$ value at $\alpha=1.5$ is close to that without NaPAA, $T_{\mathrm{m}}$ increases rapidly with $\alpha$ and reaches ca. $8{ }^{\circ} \mathrm{C}$ higher for $\alpha=10-30$ mixtures. Similar stabilization of triple helical structure was also seen for POG9 and GOO9. It should be noted that although $[\theta]_{225}$ around $T_{\mathrm{m}}$ slightly depend on the temperature changing rate $r_{\mathrm{T}},{ }^{26}$ but the difference of $T_{\mathrm{m}}$ between the mixtures and pure GPO9 are essentially the same for the two $r_{\mathrm{T}}$ 's, that is $6{ }^{\circ} \mathrm{C} \mathrm{h}^{-1}$ and $10^{\circ} \mathrm{C}$ $\mathrm{h}^{-1}$. Considering the low mass concentration of these two components, triple helical GPO9 chains should strongly interact with NaPAA even at the $T_{\mathrm{m}}$. Another interesting point is that no detectable $T_{\mathrm{m}}$ change was observed in pure water when trimer models of NaPAA (NaPAA3 and cNaPAA3 in Chart 1) were added $(\alpha \sim 30)$, showing that 'poly'electrolyte is mandatory to stabilize triple helices and suggesting that GPO9 does not form a complex with tri-valent electrolytes.
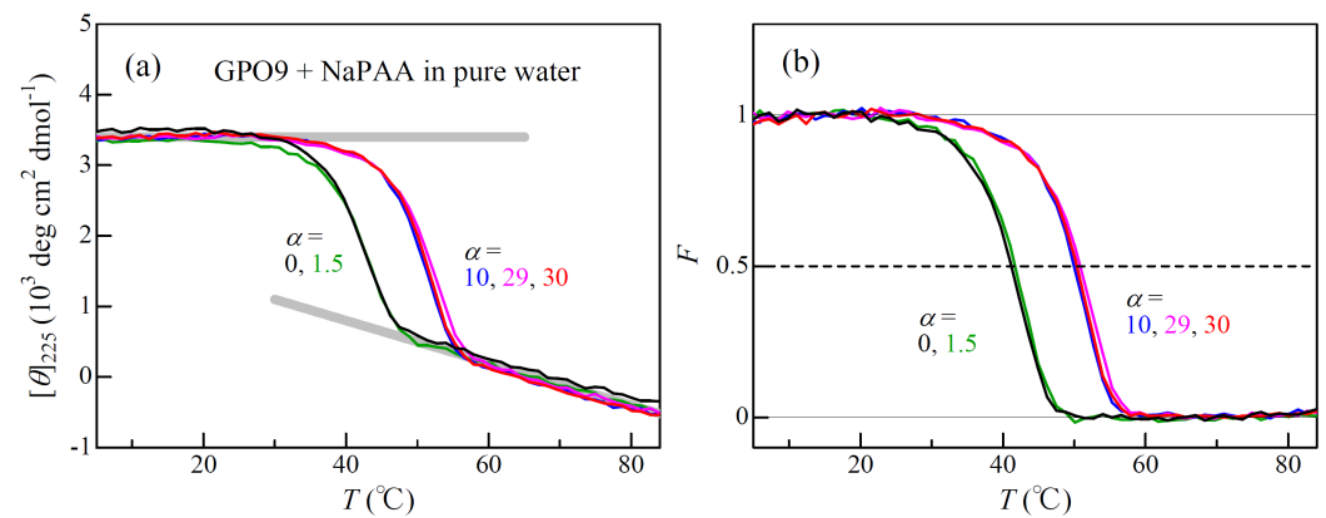

Figure 6. Temperature dependence of molar ellipticity $[\theta]_{225}$ at $\lambda_{0}=225 \mathrm{~nm}$ (a) and helix content $F$ (b) for GPO9 without or with NaPAA in pure water. Heating rates were $6{ }^{\circ} \mathrm{C} / \mathrm{h}$ and CMP mass concentration was set to be $3.0 \times 10^{-4} \mathrm{~g} \mathrm{~cm}^{-3}$. Curves are the data points for different $\alpha: \alpha=0$ (black), $\alpha=1.5$ (green), $\alpha=10$ (blue), $\alpha=29$ (magenta), $\alpha=30$ (red). 
If the thermal stabilization of triple helices with the presence of NaPAA is mainly due to the reduction of electrostatic repulsion force between three $\mathrm{N}$-termini, significant thermal stabilization is no more seen for an N-terminal capped collagen model peptide with NaPAA. A non-charged peptide Ac-(GPO6)$\mathrm{NH}_{2}$ (4 in Chart 1) is thus used instead of GPO9 and the measured temperature dependence of $F$ as shown in Figure 7. Though a relatively high $\alpha$ is chosen, the obtained $T_{\mathrm{m}}$ 's when including polyelectrolytes are essentially the same as that for pure Ac-(GPO6)- $\mathrm{NH}_{2}$, indicating that electrostatic repulsion between N-termini of GPO9, GOO9, and POG9 is screened by the anionic groups of NaPAA to increase $T_{\mathrm{m}}$. This is reasonable because $T_{\mathrm{m}}$ for GPO9 raises with increasing the saline concentration and that at $100 \mathrm{mM}$ is $4{ }^{\circ} \mathrm{C}$ higher than that in pure water (see Figure 8).

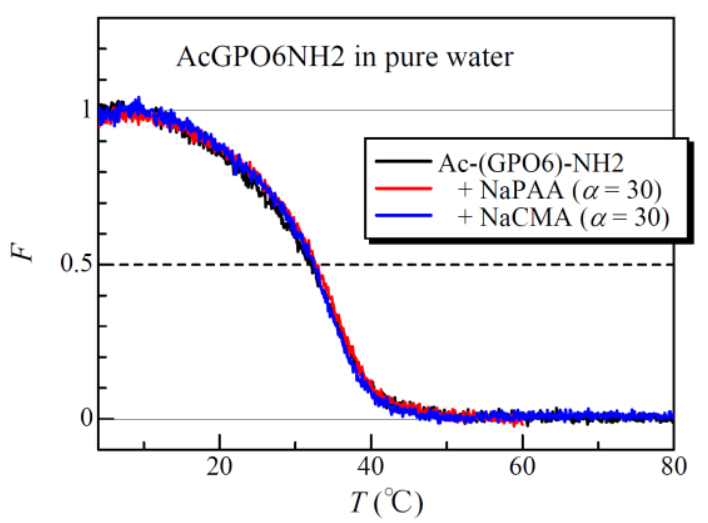

Figure 7. Temperature dependence of $F$ for Ac-(GPO6)- $\mathrm{NH}_{2}$ (black), along with those mixed with NaPAA323 (red) or NaCMA (blue) in pure water. Heating rates were $10{ }^{\circ} \mathrm{C} / \mathrm{h}$, CMP mass concentration and $\alpha$ were set to be $3.0 \times 10^{-4} \mathrm{~g} \mathrm{~cm}^{-3}$ and 30 , respectively.

Figure 8 illustrates the $\alpha$ dependence of $T_{\mathrm{m}}$ for the GPO9-NaPAA system with or without $\mathrm{NaCl}$. In pure water, $T_{\mathrm{m}}$ rapidly increases with increasing $\alpha$ and reaches an asymptotic temperature when $\alpha \geq 10$. With increasing ionic strength, the $\alpha$ dependence of $T_{\mathrm{m}}$ becomes weaker, because the triple helix is appreciably stabilized even at $\alpha=0$. In $100 \mathrm{mM}$ aqueous $\mathrm{NaCl}$, the stabilization is no more significant whereas almost all GPO9 triple helices form a complex with NaPAA in the solution. A similar trend was also obtained for mixtures of 10 times higher concentration (not shown here) being comparable to that for SAXS. Therefore, an increase in $T_{\mathrm{m}}$ in dilute solution is consistent with the complex formation, but the complex formation does not always show the increase of $T_{\mathrm{m}}$. This is probably due to the counter ions condensing around the polyelectrolyte. Consequently, it is reasonably supposed that the attractive force between GPO9 and NaPAA may weaken with increasing the ionic strength. This is consistent with the fact that the degree of complexation $f$ estimated from SAXS at $\alpha=3$ becomes lower with increasing ionic strength.

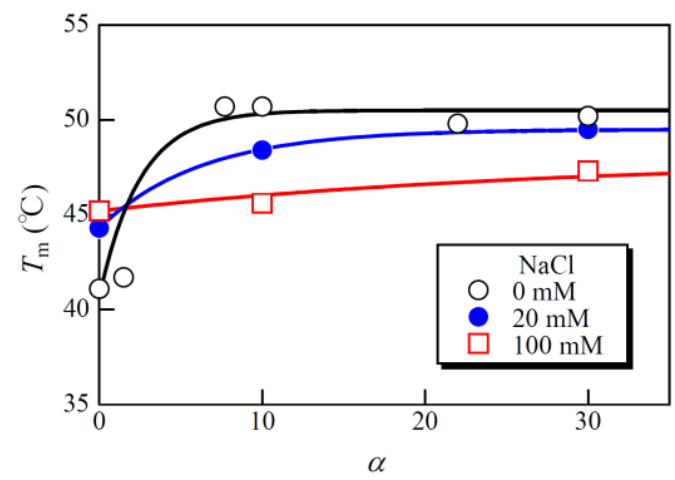

Figure 8. Composition dependence of $T_{\mathrm{m}}$ for GPO9 including NaPAA in pure water (open circles), 20 $\mathrm{mM}$ aqueous $\mathrm{NaCl}$ (filled circles), and $100 \mathrm{mM}$ (squares) aqueous $\mathrm{NaCl}$ at a temperature increasing rate of $6{ }^{\circ} \mathrm{Ch}^{-1}$. 
The stabilization of the CMP triple helix was also observed by addition of polyelectrolytes other than NaPAA, listed in Chart 1. Figure 9 compares $T_{\mathrm{m}}$ of GPO9 by addition of three different polyelectrolytes. Here, linear charge densities $c_{\mathrm{d}}$ of the polyelectrolytes added are ca. $3.8 \mathrm{~nm}^{-1}$ for NaPAA, ca. $1.9 \mathrm{~nm}^{-1}$ for NaCMA (when assuming helix pitch per residue of NaCMA is $0.32 \mathrm{~nm}$ ), ${ }^{27,28}$ and ca. $0.80 \mathrm{~nm}^{-1}$ for NaHA $^{29} T_{\mathrm{m}}$ is an increasing function of $\alpha$ in presence of the three polyelectrolytes, that is probably due to the complex formation. However, $T_{\mathrm{m}}$ increases less rapidly with decreasing $c_{\mathrm{d}}$ and the asymptotic value becomes smaller for smaller $c_{\mathrm{d}}$ polymer, indicating that not only ionic strength but also charge density of the polyelectrolytes play an important role to stabilize the triple helices of oligopeptides in the complex. It should be added that the GPO9 has $\mathrm{COO}^{-}$group at the $\mathrm{C}$-termini, which may interact with cationic groups of the polycations. Indeed, poly(vinyl ammonium) chloride (8 in Chart 1) whose $c_{\mathrm{d}}$ is essentially the same as NaPAA stabilizes triple helices almost to the same extent as the NaPAA case (see filled circles in Figure 9).

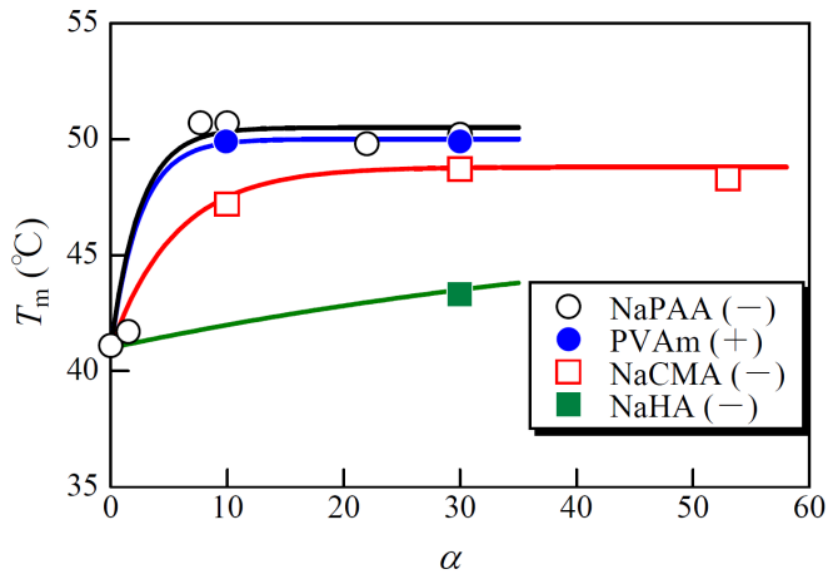

Figure 9. Composition dependence of $T_{\mathrm{m}}$ for GPO9 with NaPAA (open circles), sodium carboxymethylamylose (NaCMA, open squares), sodium hyaluronate (NaHA, filled squares), and polyvinylamine hydrochloride (PVAm, filled circles) in pure water at a temperature raising rate of $0.1{ }^{\circ} \mathrm{C} / \mathrm{min} .(-)$, Polyanion; (+), polycation.

\section{CONCLUSIONS}

Triple helical GPO9, POG9, and GOO9 form a complex with NaPAA at $15{ }^{\circ} \mathrm{C}$ whereas they are molecularly dispersed above the helix-coil transition temperature $\left(75^{\circ} \mathrm{C}\right)$. This is most likely due to the electrostatic attraction between ionized N-termini of the peptide and anionic groups of NaPAA. Indeed, this trend is more significant at lower ionic strength. Dimensional properties of the complex were successfully explained by the wormlike comb model and the NaPAA chain is found to be extended by the grafted peptide molecules. A further important point is that the triple helical structure of the peptides is stabilized by this complexation, possibly because the free positive charges at the three $\mathrm{N}$ termini destabilize the triple helical structure. This stabilization strengthens with decreasing ionic strength of solvent or increasing line charge density of polyelectrolytes. Similar stabilization was also found for GPO9 and a positively charged polyelectrolyte, indicating that ionized N-termini as well as Ctermini of the triple helices may form the complex with polyelectrolytes having opposite charge.

\section{APPENDIX: PARTICLE SCATTERING FUNCTION AND GYRATION RADIUS OF WORMLIKE COMBS WITH DIFFERENT ELECTRON DENSITY}

Nakamura and Norisuye ${ }^{21,30}$ derived the scattering function $P_{0}(q)$ for the semiflexible brushes whose side chain of the contour length $L_{\mathrm{s}}$ is linked to the main chain of the contour length $L_{\mathrm{m}}$ by a universal joint in the same manner as Huber and Burchard's for wormlike stars. ${ }^{31}$ 


$$
\begin{aligned}
& P_{0}(q)=\frac{1}{\left(L_{\mathrm{m}}+p L_{\mathrm{s}}\right)^{2}} \sum_{i} \sum_{j} \int d s_{i} \int d s_{i}\langle\exp [i \mathbf{q} \cdot \mathbf{R}(s i, s j)]\rangle \\
& =\frac{2\left[J_{1}\left(k ; L_{\mathrm{m}}, \lambda_{\mathrm{m}}\right)+J_{2}\left(k ; p, L_{\mathrm{s}}, \lambda_{\mathrm{s}}\right)+J_{3}\left(k ; p, L_{\mathrm{s}}, L_{\mathrm{m}}, \lambda_{\mathrm{s}}, \lambda_{\mathrm{m}}\right)+J_{4}\left(k ; p, L_{\mathrm{s}}, L_{\mathrm{m}}, \lambda_{\mathrm{s}}, \lambda_{\mathrm{m}}\right)\right]}{\left(L_{\mathrm{m}}+p L_{\mathrm{s}}\right)^{2}}
\end{aligned}
$$

Here, $p$ is the number of side chains $(=n / 3 \alpha)$, $\mathbf{q}$ is the scattering vector, and $\mathbf{R}\left(s_{i}, s_{j}\right)$ is the vector between the contour points $\mathbf{R}\left(s_{i}\right)$ and $\mathbf{R}\left(s_{j}\right)$ on the subchains $i$ and $j$, respectively, at the contour distances $s_{i}$ and $s_{j}$, measured from one ends of the subchains. The subchain is a side chain or a portion of the main chain lain between neighboring junction points. The summation can be decomposed into the four terms, $J_{1}$ (both $\mathbf{R}\left(s_{\mathrm{i}}\right)$ and $\mathbf{R}\left(s_{\mathrm{j}}\right)$ are on the main chain), $J_{2}$ (both $\mathbf{R}\left(s_{\mathrm{i}}\right)$ and $\mathbf{R}\left(s_{\mathrm{j}}\right)$ are on the same side chain), $J_{3}\left(\mathbf{R}\left(s_{\mathrm{i}}\right)\right.$ is on the main chain and $\mathbf{R}\left(s_{\mathrm{j}}\right)$ is on a side chain), and $J_{4}\left(\mathbf{R}\left(s_{\mathrm{i}}\right)\right.$ and $\mathbf{R}\left(s_{\mathrm{j}}\right)$ are on different side chains) (see eqs $79-82$ in ref 30 for the details on $J_{1}, J_{2}, J_{3}$, and $J_{4}$ ). Here, $\lambda_{\mathrm{s}}{ }^{-1}$ and $\lambda_{\mathrm{m}}{ }^{-1}$ are the Kuhn segment lengths of the side chain (i.e., CMP) and main chain (NaPAA), respectively.

Equation 8 is however applicable only when the SAXS contrast factors per unit contour length of the side chain $\Delta z_{\mathrm{s}} M_{\mathrm{L}, \mathrm{s}}$ and of the main chain $\Delta z_{\mathrm{m}} M_{\mathrm{L}, \mathrm{m}}$ are the same, where, $M_{\mathrm{L}, \mathrm{s}}\left(\equiv M_{\mathrm{s}} / L_{\mathrm{s}}\right)$ and $M_{\mathrm{L}, \mathrm{m}}(\equiv$ $\left.M_{\mathrm{m}} / L_{\mathrm{m}}\right)$ are the molar masses per unit contour length of the side chain and main chain, respectively. In our case, the value $\Delta z_{\mathrm{s}} M_{\mathrm{L}, \mathrm{s}}$ for the triple helical GPO9 is $46 \%$ larger than that $\Delta z_{\mathrm{m}} M_{\mathrm{L}, \mathrm{m}}$ for NaPAA, so that we extend eq 8 as

$$
\begin{aligned}
& P_{0}(q)=\frac{1}{\left(\Delta z_{\mathrm{m}} M_{\mathrm{m}}+p \Delta z_{\mathrm{s}} M_{\mathrm{s}}\right)^{2}} \sum_{i} \sum_{j} \int d s_{i} \int d s_{j} \Delta z_{i} M_{\mathrm{L}, i} \Delta z_{j} M_{\mathrm{L}, j}\left\langle\exp \left[i \mathbf{q} \cdot \mathbf{R}\left(s_{i}, s_{j}\right)\right]\right\rangle \\
& =\frac{\left[\begin{array}{l}
\left(\Delta z_{\mathrm{m}} M_{\mathrm{L}, \mathrm{m}}\right)^{2} J_{1}\left(k ; L_{\mathrm{m}}, \lambda_{\mathrm{m}}\right)+\left(\Delta z_{\mathrm{s}} M_{\mathrm{L}, \mathrm{s}}\right)^{2} J_{2}\left(k ; p, L_{\mathrm{s}}, \lambda_{\mathrm{s}}\right) \\
+\Delta z_{\mathrm{s}} \Delta z_{\mathrm{m}} M_{\mathrm{L}, \mathrm{s}} M_{\mathrm{L}, \mathrm{m}} J_{3}\left(k ; p, L_{\mathrm{s}}, L_{\mathrm{m}}, \lambda_{\mathrm{s}}, \lambda_{\mathrm{m}}\right)+\left(\Delta z_{\mathrm{s}} M_{\mathrm{L}, \mathrm{s}}\right)^{2} J_{4}\left(k ; p, L_{\mathrm{s}}, L_{\mathrm{m}}, \lambda_{\mathrm{s}}, \lambda_{\mathrm{m}}\right)
\end{array}\right]}{\left(\Delta z_{\mathrm{m}} M_{\mathrm{m}}+p \Delta z_{\mathrm{s}} M_{\mathrm{s}}\right)^{2}}
\end{aligned}
$$

to calculate $P_{3}(q)$ for the GPO9-NaPAA complex. Likewise, the radius of gyration for the complex can be calculated by

$$
\left\langle S^{2}\right\rangle=\frac{\left[\begin{array}{l}
\left(\Delta z_{\mathrm{m}} M_{\mathrm{L}, \mathrm{m}}\right)^{2} I_{1}\left(L_{\mathrm{m}}, \lambda_{\mathrm{m}}\right)+\left(\Delta z_{\mathrm{s}} M_{\mathrm{L}, \mathrm{s}}\right)^{2} I_{2}\left(p, L_{\mathrm{s}}, \lambda_{\mathrm{s}}\right) \\
+\Delta z_{\mathrm{s}} \Delta z_{\mathrm{m}} M_{\mathrm{L}, \mathrm{s}} M_{\mathrm{L}, \mathrm{m}} I_{3}\left(p, L_{\mathrm{s}}, L_{\mathrm{m}}, \lambda_{\mathrm{s}}, \lambda_{\mathrm{m}}\right)+\left(\Delta z_{\mathrm{s}} M_{\mathrm{L}, \mathrm{s}}\right)^{2} I_{4}\left(p, L_{\mathrm{s}}, L_{\mathrm{m}}, \lambda_{\mathrm{s}}, \lambda_{\mathrm{m}}\right)
\end{array}\right]}{\left(\Delta z_{\mathrm{m}} M_{\mathrm{m}}+p \Delta z_{\mathrm{s}} M_{\mathrm{s}}\right)^{2}}
$$

where $I_{1}, I_{2}, I_{3}$, and $I_{4}$ are listed as eqs $69-72$ in ref 30 .

In the case of the GPO9-NaPAA complex, the chain diameter $d(=1.6 \mathrm{~nm})$ of NaPAA is almost equivalent to that for triple helical GPO $9,{ }^{19}$ the chain thickness for the complex can be considered according to the following equation for the touched-bead model with the same bead diameter $d_{\mathrm{B}}$ both for NaPAA and triple helical GPO9. ${ }^{32}$

$$
P_{3}(q)=9\left(\frac{2}{q d_{\mathrm{B}}}\right)^{6}\left[\sin \left(q d_{\mathrm{B}} / 2\right)-\left(q d_{\mathrm{B}} / 2\right) \cos \left(q d_{\mathrm{B}} / 2\right)\right]^{2} P_{0}(q)
$$

It should be noted that this chain thickness is not appreciable for $\left\langle S^{2}\right\rangle$ when we estimate the contribution in $<S^{2}>$ by $d^{2} / 8 .^{33}$ 
Acknowledgment. The synchrotron radiation experiments were performed at the BL40B2 in SPring8 with the approval of the Japan Synchrotron Radiation Research Institute (JASRI) (Proposal \#2010B1126) and at the BL-10C in KEK-PF under the approval of the Photon Factory Program Advisory Committee (\#2010G080). The authors thank Prof. Yoji Inoko (Osaka Univ.) for SAXS measurements in KEK-PF and Prof. Shinichi Kitamura (Osaka Pref. Univ.) for supplying an enzymatically synthesized amylose sample. K. T. is indebted to the Institutional Program for Young Researcher Overseas Visits, Japan Society of the Promotion of Science (JSPS).

Supporting Information Available. Circular dichroism spectra for GPO9 with or without NaPAA. This material is available free of charge via the Internet at http://pubs.acs.org.

\section{REFERENCES}

(1) Fallas, J. A.; O’Leary, L. E. R.; Hartgerink, J. D. Chem. Soc. Rev. 2010, 39, 3510-3527.

(2) Fields, G. B. Org. Biomol. Chem. 2010, 8, 1237-1258.

(3) Shoulders, M. D.; Raines, R. T. Ann. Rev. Biochem. 2009, 78, 929-958.

(4) Berisio, R.; De Simone, A.; Ruggiero, A.; Improta, R.; Vitagliano, L. J. Pept. Sci. 2009, 15, 131140.

(5) Okuyama, K.; Kawaguchi, T. Kobunshi Ronbunshu 2010, 67, 229-247.

(6) Okuyama, K. Connect. Tissue Res. 2008, 49, 299-310.

(7) Kita, Y.; Terao, K.; Sato, T. Kobunshi Ronbunshu 2010, 67, 686-689.

(8) Feng, Y.; Melacini, G.; Taulane, J. P.; Goodman, M. J. Am. Chem. Soc. 1996, 118, 10351-10358.

(9) Locardi, E.; Kwak, J.; Scheraga, H. A.; Goodman, M. J. Phys. Chem. A. 1999, 103, 10561-10566.

(10) Frank, S.; Boudko, S.; Mizuno, K.; Schulthess, T.; Engel, J.; Bächinger, H. P. J. Biol. Chem. 2003, 278, 7747-7750.

(11) Suehiro, T.; Tada, T.; Waku, T.; Tanaka, N.; Hongo, C.; Yamamoto, S.; Nakahira, A.; Kojima, C. Biopolymers 2011, 95, 270-277.

(12) Mizuno, K.; Hayashi, T.; Peyton, D. H.; Bächinger, H. P. J. Biol. Chem. 2004, 279, 38072-38078.

(13) Mizuse, M. M.S. thesis, Osaka University: Osaka, Japan, 2010.

(14) (a) Kitamura, S.; Yunokawa, H.; Mitsuie, S.; Kuge, T. Polym. J. 1982, 14, 93-99. (b) Waldmann, H.; Gygax, D.; Bednarski, M. D.; Shangraw, W. R.; Whitesides, G. M. Carbohydr. Res. 1986, 157, c4c7.

(15) Dubin, P.; Brant, D. A. Macromolecules 1975, 8, 831-842.

(16) Heinze, T.; Pfeiffer, K. ; Lazik, W. J. Appl. Polym. Sci. 2001, 81, 2036-2044.

(17) Ueno, K.; Ueno, H.; Sato, T. Polym. J. in press (doi:10.1038/pj.2011.65).

(18) Glatter, O.; Kratky, O. Small Angle X-ray Scattering; Academic Press: London, 1982.

(19) Terao, K.; Mizuno, K.; Murashima, M.; Kita, Y.; Hongo, C.; Okuyama, K.; Norisuye, T.;

Bächinger, H. P. Macromolecules 2008, 41, 7203-7210.

(20) Berry, G. C. J. Chem. Phys. 1966, 44, 4550-4564.

(21) Nakamura, Y.; Wan, Y.; Mays, J. W.; Iatrou, H.; Hadjichristidis, N. Macromolecules 2000, 33, 8323-8328.

(22) Terao, K.; Farmer, B. S.; Nakamura, Y.; Iatrou, H.; Hong, K.; Mays, J. W. Macromolecules 2005, $38,1447-1450$.

(23) Nakamura, Y.; Norisuye, T. J. Polym. Sci., Part B: Polym. Phys. 2004, 42, 1398-1407.

(24) (a) Schweins, R.; Hollmann, J.; Huber, K. Polymer 2003, 44, 7131-7141. (b) Muroga, Y.; Noda, I.; Nagasawa, I. Macromolecules 1985, 18, 1576-1579. (c) Knappe, P.; Bienert, R.; Weidner, S.;

Thünemann, A. F. Macromol. Chem. Phys. 2010, 211, 2148-2153.

(25) Noda, I.; Tsuge, T.; Nagasawa, M. J. Phys. Chem. 1970, 74, 710-719.

(26) Mizuno, K.; Boudko, S.; Engel, J.; Bächinger, H. P. Biophys. J. 2010, 98, 3004-3014.

(27) Nakanishi, Y.; Norisuye, T.; Teramoto, A.; Kitamura, S. Macromolecules 1993, 26, 4220-4225.

(28) Norisuye, T. Polym. J. 1994, 26, 1303-1307. 
(29) Hayashi, K.; Tsutsumi, K.; Nakajima, F.; Norisuye, T.; Teramoto, A. Macromolecules 1995, 28, 3824-3830.

(30) Nakamura, Y.; Norisuye, T. In Soft-Matter Characterization; Borsali, R.; Pecora, R. Eds.; Springer: Berlin, 2008; Vol. 1, p 236-286.

(31) Huber, K.; Burchard, W. Macromolecules 1989, 22, 3332-3336.

(32) Burchard, W.; Kajiwara, K. Proc. R. Soc. London, Ser. A. 1970, 316, 185-199.

(33) Konishi, T.; Yoshizaki, T.; Saito, T.; Einaga, Y.; Yamakawa, H. Macromolecules 1990, 23, 290 297. 
For Table of Contents Use Only

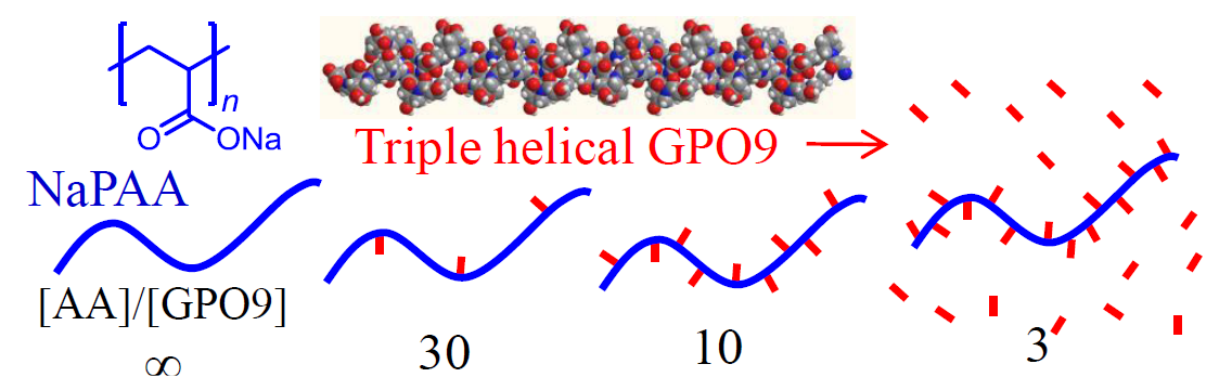

Complex Formation of Collagen Model Peptides with Polyelectrolytes and Stabilization of the Triple Helical Structure

Ken Terao, Ryoko Kanenaga, Takahiro Sato, Kazunori Mizuno, and Hans Peter Bächinger 